\title{
Can tumor size be a guide for limited surgical intervention in patients with peripheral non-small cell lung cancer? Assessment from the point of view of nodal micrometastasis
}

\author{
Yasuhiko Ohta, MDa,c \\ Makoto Oda, MDa \\ Jian $\mathrm{Wu}, \mathrm{MD}^{\mathrm{a}}$ \\ Yoshio Tsunezuka, MDa \\ Minato Hiroshi, MD \\ Akitaka Nonomura, MD \\ Go Watanabe, MDa
}

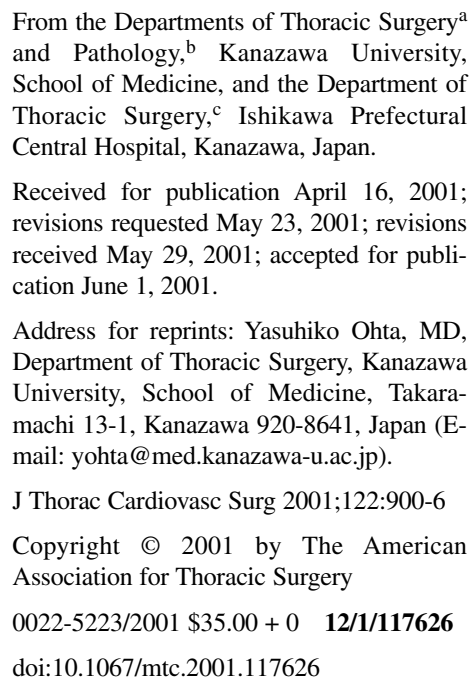

Received for publication April 16, 2001; revisions requested May 23, 2001; revisions received May 29, 2001; accepted for publication June 1, 2001.

Address for reprints: Yasuhiko Ohta, MD, Department of Thoracic Surgery, Kanazawa University, School of Medicine, Takaramachi 13-1, Kanazawa 920-8641, Japan (Email: yohta@med.kanazawa-u.ac.jp).

J Thorac Cardiovasc Surg 2001;122:900-6

Copyright @ 2001 by The American Association for Thoracic Surgery

0022-5223/2001 $\$ 35.00+0 \quad \mathbf{1 2 / 1 / 1 1 7 6 2 6}$

doi:10.1067/mtc.2001.117626

Objective: We sought to determine the critical diameter of a peripheral non-small cell lung cancer tumor less than which no evidence of nodal micrometastasis is present.

Methods: Samples of 3081 lymph nodes from 181 patients with stage I peripheral lung cancer (155 with adenocarcinoma and 26 with squamous cell carcinoma) who had undergone complete resection with systematic lymphadenectomy were used in the study. In the samples immunohistochemical staining for cytokeratin was performed. The expression of vascular endothelial growth factor (VEGF) at primary sites was also immunohistochemically assessed.

Results: Nodal micrometastasis was detected in 44 patients. The mean tumor sizes were $2.2 \pm 1.3 \mathrm{~cm}$ (range, $1.0-7.0 \mathrm{~cm}$ ) in nodal micrometastasis-positive adenocarcinoma, $2.1 \pm 0.9 \mathrm{~cm}$ (range, $0.5-6.0 \mathrm{~cm}$ ) in nodal micrometastasis-negative adenocarcinoma, $4.8 \pm 2.3 \mathrm{~cm}$ (range, $2.2-10.0 \mathrm{~cm}$ ) in nodal micrometastasis-positive squamous cell carcinoma, and $3.2 \pm 2.1 \mathrm{~cm}$ (range, $0-9.0 \mathrm{~cm}$ ) in nodal micrometastasis-negative squamous cell carcinoma. The tumor size in the nodal micrometastasis-positive group tended to be greater than that in the nodal micrometastasisnegative group in squamous cell carcinomas, but there was no significant difference in adenocarcinomas. Nodal micrometastasis was not found in patients with squamous cell carcinoma of $2.0 \mathrm{~cm}$ or less in diameter. However, nodal micrometastasis was found in $20 \%$ (19/95) of the patients with adenocarcinoma of 1.1 to $2.0 \mathrm{~cm}$ in diameter and even in 4 of 11 patients with adenocarcinoma of $1.0 \mathrm{~cm}$ or less. Among the patients with nodal micrometastasis, survival of patients with vascular endothelial growth factor overexpression was worse than that of patients without it. The survival of patients with nodal micrometastasis without vascular endothelial growth factor overexpression was comparable with that of patients without nodal micrometastasis.

Conclusion: A limited surgical intervention without lymphadenectomy is validated for squamous cell carcinoma of $2.0 \mathrm{~cm}$ or less without pleural involvement. In adenocarcinoma the tumor size itself is not a reliable guide for nodal micrometastasis status. In patients with nodal micrometastasis with vascular endothelial growth factor overexpression, the risk of systemic disease should be considered. 


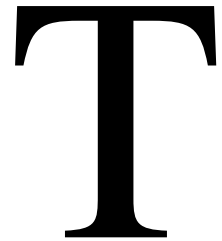

he presence of nodal metastasis has a decisive meaning for the postoperative outcome of patients with lung cancer. Of importance, recent studies have revealed that the presence of microdissemination of cancer cells in lymph nodes has a significantly negative effect on survival of patients with lung cancer despite systemic lymphadenectomy, generally resulting in distant relapse, even after a curative operation. ${ }^{1-4}$ A plausible explanation for this matched interrelation between microdissemination of cancer cells in lymph nodes and dismal clinical outcome after complete resection is that the small amount of cancer cells detected as a single or clustered formation in nodes is a premanifestation state of metastasis, and some of them have a risk of systemic disease. Recently, with the advent of computed tomography (CT) scanning for screening for lung cancer, thoracic surgeons have often begun to encounter cases of small-sized peripheral lung cancer. However, we do not yet know whether the primary lung tumor size can be used as a basis for the selection of limited surgical intervention from the point of view of nodal micrometastasis (NM). Moreover, identification of micrometastasis with a risk of development of systemic disease is necessary to put forward adjuvant therapies in patients with early stage lung cancer. This study was undertaken to ascertain whether there is a critical diameter of a peripheral non-small cell lung cancer (NSCLC) tumor less than which no evidence of NM is found.

\section{Methods \\ Patients}

A total of 3081 lymph nodes were obtained from 181 randomly selected patients with stage I NSCLC of the peripheral type who had undergone complete resection with systematic lymphadenectomy at Kanazawa University Hospital from 1986 to 1996. The 181 patients included 94 men and 87 women with a mean age of $63.7 \pm 9.6$ years (range, $38-84$ years; median, 65 years). The pathologic types were 155 adenocarcinomas and 26 squamous cell carcinomas. According to the TNM classification, 148 patients had tumors of $3 \mathrm{~cm}$ or less in diameter (T1 N0 M0 disease) and 33 patients had tumors greater than $3 \mathrm{~cm}$ (T2 N0 M0 disease). Table 1 shows the basic clinical features of the patients. Informed consent was obtained from all patients for the use of both primary tumor and lymph node samples.

\section{Immunohistochemistry for Detection of Micrometastasis}

The existence of cancer cells within lymph nodes was examined by using immunohistochemical staining for cytokeratin, as described previously. ${ }^{5}$ In brief, after deparaffinization of $4-\mu \mathrm{m}$ thick paraffin sections obtained from lymph node samples, the sections were boiled for 5 minutes in $0.01 \mathrm{~mol} / \mathrm{L}$ sodium citrate solution ( $\mathrm{pH}$ 6.0) in a microwave oven 3 times. Endogenous peroxidase was blocked by treatment with $0.3 \%$ hydrogen peroxide in methanol for 15 minutes. The sections were incubated with normal goat serum diluted 10-fold with phosphate-buffered saline solution for 15 minutes for blocking. After incubation, the sections were reacted with anti-AE1/AE3 antibody (DAKO, Carpinteria, Calif) that had been diluted 50-fold with phosphate-buffered saline solution for 1 hour at room temperature, and then they were reacted with biotinlabeled goat anti-mouse immunoglobulin (DAKO) for 2 hours. After adding avidin-biotin-peroxidase complex, color was developed with 3-3 diaminobenzidine (Sigma Chemical Co, St Louis, Mo) and $0.03 \%$ hydrogen peroxide. Counterstaining was done with hematoxylin and eosin. In this study both single and clustered tumor cells with a size of not more than $2 \mathrm{~mm}$ were defined as micrometastases, taking into consideration morphologic features. $^{2,6}$ Positivity was blindly evaluated by 2 independent observers, including a pathologist without knowledge of the clinicopathologic factors.

\section{Immunohistochemical Assessment of Vascular Endothelial Growth Factor}

The expression of vascular endothelial growth factor (VEGF) in cancer cells at the primary site was also immunohistochemically assessed by using the labeled streptavidin-biotin method, as described previously. $5,7,8$ For the primary antibody, we used the anti-VEGF polyclonal antibody (Santa Cruz Biotechnology Inc, Heidelberg, Germany) diluted 100-fold. Paraffin-embedded sections of the invasive edges of the tumors were reacted with the antibody for 2 hours at room temperature. The second antibody used was biotin-labeled goat anti-mouse immunoglobulin (DAKO). A tumor with more than $50 \%$ positive staining area of cancer cells was defined as a VEGF-overexpressing tumor. ${ }^{5,8}$

\section{Statistics}

The association between variables was analyzed with the $\chi^{2}$ test. The Mann-Whitney $U$ test for difference in the mean values was used for comparison of nominal data. Survival curves were obtained by the Kaplan-Meier method and compared by the logrank test. NM, age ( $\geq 65$ vs $<65$ years), sex, $T$ factor (T1 vs T2), pathologic type, differentiation of tumors (poorly vs moderately or well), blood vessel invasion, lymphatic vessel invasion, and VEGF were included in the assessment of prognostic indicators. Both univariate and multivariate analyses were performed with the Cox proportional hazard model. Values are given as means \pm SD. The data were analyzed with a statistical software package (StatView; Abacus Concepts, Inc, Berkeley, Calif).

\section{Results}

Positive staining for AE1/AE3 was confirmed in both normal epithelial and tumor cells in primary sites in all cases. CK-positive cancer cells were detected in lymph nodes in 44 $(24.3 \%)$ patients. Most of the disseminated cancer cells showed clustered formation at the edges of the nodes. Thirty-two of these 44 patients had micrometastasis in a single nodal station, and 12 patients had micrometastasis at multiple levels. On the basis of the sites of affected lymph nodes, 19 patients had N1 disease, and 25 patients had N2 disease. As shown in Table 1, there were no significant differences in the percentages of patients with and without NM 
TABLE 1. Correlation of clinicopathologic features with modal micrometastasis (NM)

\begin{tabular}{|c|c|c|c|c|c|c|c|c|c|}
\hline \multirow[b]{2}{*}{ Factors } & \multicolumn{2}{|c|}{ Total $(n=181)$} & \multirow[b]{2}{*}{$P$ value } & \multicolumn{2}{|c|}{ Adenocarcinoma } & \multirow[b]{2}{*}{$P$ value } & \multicolumn{2}{|c|}{ Squamous cell carcinoma } & \multirow[b]{2}{*}{$P$ value } \\
\hline & NM(+) & NM(-) & & $N M(+)$ & $\mathbf{N M}(-)$ & & $N M(+)$ & $\mathbf{N M}(-)$ & \\
\hline Patients & 44 & 137 & & 34 & 121 & & 10 & 16 & \\
\hline Sex & & & .8918 & & & .5397 & & & .1971 \\
\hline Male & 23 & 70 & & 14 & 54 & & 9 & 16 & \\
\hline Female & 21 & 67 & & 20 & 67 & & 1 & 0 & \\
\hline Mean $\pm S D$ age $(y)$ & $64.5 \pm 8.6$ & $63.6 \pm 9.8$ & .5921 & $63.3 \pm 8.6$ & $63.2 \pm 9.9$ & .9053 & $68.6 \pm 7.7$ & $66.1 \pm 8.5$ & .5747 \\
\hline T factor & & & .0552 & & & .9751 & & & .0344 \\
\hline $\mathrm{T} 1$ & 32 & 117 & & 30 & 107 & & 2 & 10 & \\
\hline $\mathrm{T} 2$ & 12 & 20 & & 4 & 14 & & 8 & 6 & \\
\hline Differentiation & & & .0045 & & & .0020 & & & .9373 \\
\hline Well-moderate & 34 & 127 & & 26 & 114 & & 8 & 13 & \\
\hline Poor & 10 & 10 & & 8 & 7 & & 2 & 3 & \\
\hline \multicolumn{10}{|l|}{ Location of primary tumor } \\
\hline Right & 28 & 96 & .4239 & 21 & 87 & .1809 & 7 & 9 & .4832 \\
\hline Left & 16 & 41 & & 13 & 34 & & 3 & 7 & \\
\hline Upper lobe & 30 & 82 & .6618 & 25 & 73 & .2780 & 5 & 9 & .6217 \\
\hline Middle lobe & 2 & 12 & & 2 & 11 & & 0 & 1 & \\
\hline Lower lobe & 12 & 43 & & 7 & 37 & & 5 & 6 & \\
\hline Lymphatic vessel invasion & & & .0060 & & & .0025 & & & .8989 \\
\hline Positive & 25 & 44 & & 21 & 38 & & 4 & 6 & \\
\hline Negative & 19 & 93 & & 13 & 83 & & 6 & 10 & \\
\hline Blood vessel invasion & & & .0833 & & & .0590 & & & .8506 \\
\hline Positive & 20 & 41 & & 16 & 34 & & 4 & 7 & \\
\hline Negative & 24 & 96 & & 18 & 87 & & 6 & 9 & \\
\hline
\end{tabular}

TABLE 2. Primary tumor size and NM status

\begin{tabular}{|c|c|c|c|c|c|c|}
\hline & \multicolumn{3}{|c|}{ Adenocarcinoma ( $n=155$ ) } & \multicolumn{3}{|c|}{ Squamous cell carcinoma ( $n=26$ ) } \\
\hline & $\leq 1.0 \mathrm{~cm}$ & $1.1-2.0 \mathrm{~cm}$ & $\geq 2.1 \mathrm{~cm}$ & $\leq 1.0 \mathrm{~cm}$ & $1.1-2.0 \mathrm{~cm}$ & $\geq 2.1 \mathrm{~cm}$ \\
\hline NM positive (n) & 4 & 19 & 11 & 0 & 0 & 10 \\
\hline NM negative (n) & 7 & 76 & 38 & 2 & 4 & 10 \\
\hline
\end{tabular}

according to age, sex, location of the primary tumor (right vs left, upper lobe vs lower lobe), and pathologic type (adenocarcinoma vs squamous cell carcinoma). In adenocarcinoma the incidence of NM was significantly higher in the patients with poorly differentiated tumors than in those with well or moderately differentiated tumors $(P=.002)$. The incidence of NM was significantly higher in tumors with lymphatic vessel invasion than in tumors without it $(P=$ .006). In squamous cell carcinoma the $\mathrm{T}$ factor affected the NM incidence $(P=.0344)$. Of 155 patients with adenocarcinoma, $34(21.9 \%)$ had NM, and of 26 patients with squamous cell carcinomas, $10(38.5 \%)$ had NM. NM outside the regional lymph nodes (ie, skipping metastasis) was detected in $25(56.8 \%)$ patients. In patients with the primary tumor in an upper lobe, NM was mainly detected in the upper mediastinal area. However, in 3 of 18 patients with the primary tumor in the right upper lobe, spread of NM to the lower mediastinal area (subcarinal nodal involvement) was found.
In patients with tumors in the left lower lobe, NM was mainly found in the lower mediastinal area. In 4 of 6 patients with tumors in the right lower lobe, NM was found in the upper mediastinal area.

The mean tumor sizes, according to NM status and pathologic type, were $2.2 \pm 1.3 \mathrm{~cm}$ (range, 1.0-7.0 cm) in NM-positive adenocarcinoma, $2.1 \pm 0.9 \mathrm{~cm}$ (range, 0.5-6.0 $\mathrm{cm}$ ) in NM-negative adenocarcinoma, $4.8 \pm 2.3 \mathrm{~cm}$ (range, $2.2-10.0 \mathrm{~cm}$ ) in NM-positive squamous cell carcinoma, and $3.2 \pm 2.1 \mathrm{~cm}$ (range, $0-9.0 \mathrm{~cm}$ ) in NM-negative squamous cell carcinoma. The mean primary tumor size in the NMpositive group tended to be greater than that in the NM-negative group in squamous cell carcinomas $(P=.0651)$, but no significant difference was found in adenocarcinomas $(P=$ $.9655)$. In patients with squamous cell carcinoma of $2.0 \mathrm{~cm}$ or less in diameter, NM was not found (0/6). However, of the 20 patients with squamous cell carcinoma of more than $2.0 \mathrm{~cm}$ in diameter, $10(50 \%)$ patients had micrometastasis. 


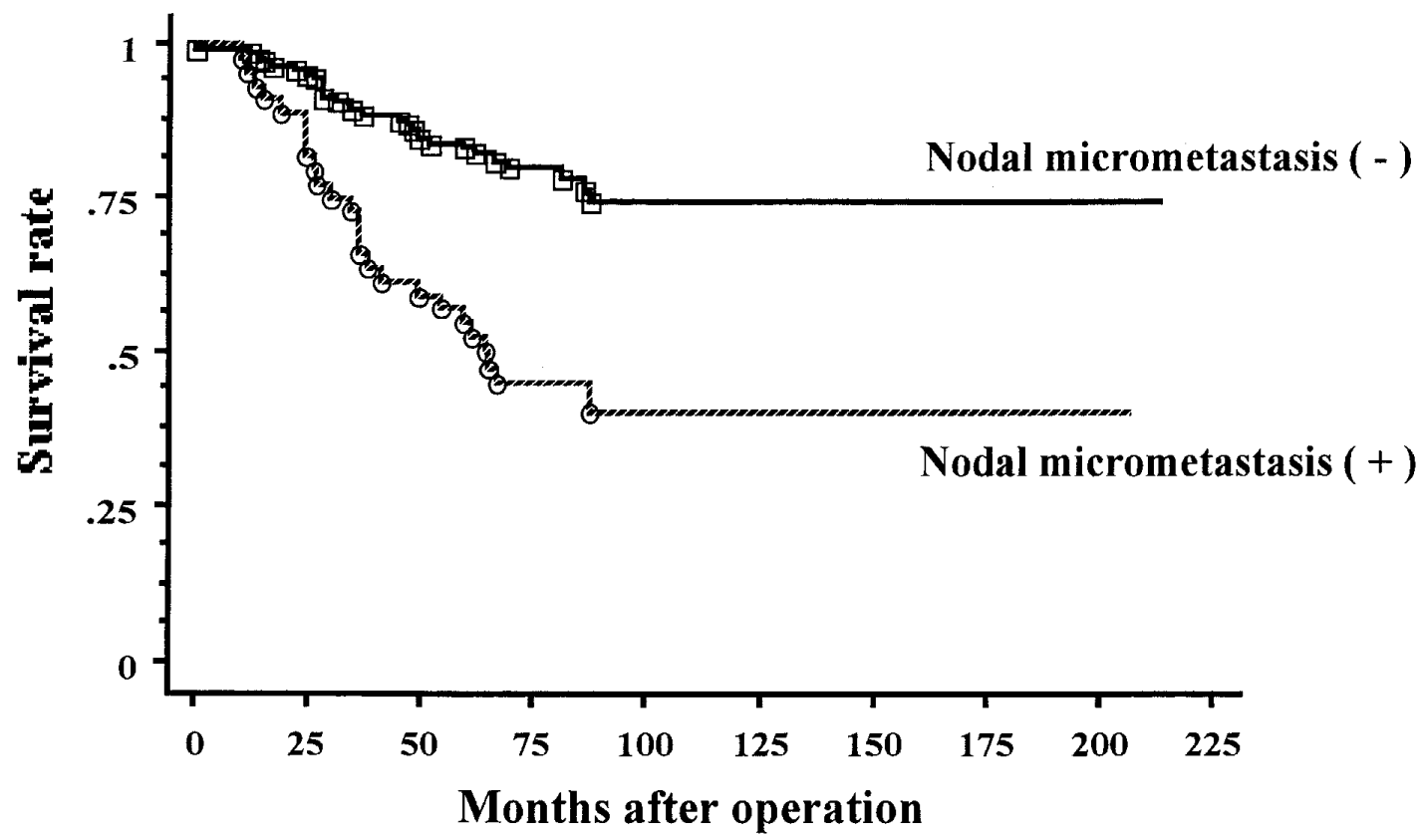

Figure 1. Kaplan-Meier survival plots for 181 patients with peripheral stage I NSCLCs subdivided according to NM status. The difference in survival between the NM-positive group $(n=44)$ and the NM-negative group ( $n=$ 137) was significant $(P<.0001)$.

TABLE 3. Patients with peripheral adenocarcinoma of $1.0 \mathrm{~cm}$ in diameter

\begin{tabular}{|c|c|c|c|c|c|c|c|c|}
\hline $\begin{array}{l}\text { Patient } \\
\text { No. }\end{array}$ & Sex & Age (y) & $\begin{array}{c}\text { Primary } \\
\text { tumor size } \\
\text { (cm) }\end{array}$ & $\begin{array}{l}\text { Location } \\
\text { of primary } \\
\text { tumor }\end{array}$ & $\begin{array}{c}\text { Nodal station } \\
\text { of NM } \\
\text { (No. of } \\
\text { positive node) }\end{array}$ & $\begin{array}{c}\text { Lymphatic } \\
\text { vessel } \\
\text { invasion }\end{array}$ & $\begin{array}{c}\text { Blood } \\
\text { vessel } \\
\text { invasion }\end{array}$ & $\begin{array}{c}\text { Outcome } \\
\text { (mo) }\end{array}$ \\
\hline 1 & Female & 69 & 1.0 & RUL & $13(1)$ & Negative & Negative & Alive (163) \\
\hline 2 & Male & 59 & 1.0 & LUL & $12(1)$ & Negative & Negative & Alive (100) \\
\hline 3 & Female & 55 & 1.0 & RUL & $11(1)$ & Positive & Negative & Alive (99) \\
\hline 4 & Male & 59 & 1.0 & RUL & $1(1)$ & Positive & Positive & Alive (87) \\
\hline
\end{tabular}

$R U L$, Right upper lobe; $L U L$, left upper lobe.

The incidence of NM in patients with adenocarcinoma of $1.1 \mathrm{~cm}$ to $2.0 \mathrm{~cm}$ in diameter was $20 \%$ (19/95). Of the 11 patients with adenocarcinoma of $1.0 \mathrm{~cm}$ or less in diameter, 4 had NM (Table 2). Primary tumor size was $1.0 \mathrm{~cm}$ in all 4 cases, and NM was detected at a single level. In 3 of the 4 patients, the affected nodal station was localized within the segmental area, and all 4 patients survived after standard resection (lobectomy) plus systematic lymph node dissection (Table 3).

There was no significant difference between survivals of patients with adenocarcinomas and those with squamous cell carcinomas $(P=.324)$. The 5- and 10-year survivals of patients were $54.5 \%$ and $40.2 \%$, respectively, in the NMpositive group $(n=44)$ and $82.4 \%$ and $74.8 \%$, respectively, in the NM-negative group $(\mathrm{n}=137 ; P<.0001$, Figure 1$)$.

The immunohistochemical staining for VEGF was performed in 177 patients in total. VEGF antigens were mainly identified in the cytoplasm of tumor cells and vascular endothelial cells, as we previously reported..$^{5,8}$ The percentage of patients with VEGF overexpression was $57.6 \%$ $(102 / 177)$ in total. The percentage of patients with VEGF overexpression in the NM-positive group was significantly higher than that in the NM-negative group $(74.4 \%$ vs $52.2 \%, P=.0165)$. Among the patients with NM, survival of patients with VEGF overexpression was worse than that of patients without it $(P<.0001)$. However, the survival of patients with NM without VEGF overexpression was almost equivalent to that of patients without NM (Figure 2). Among 


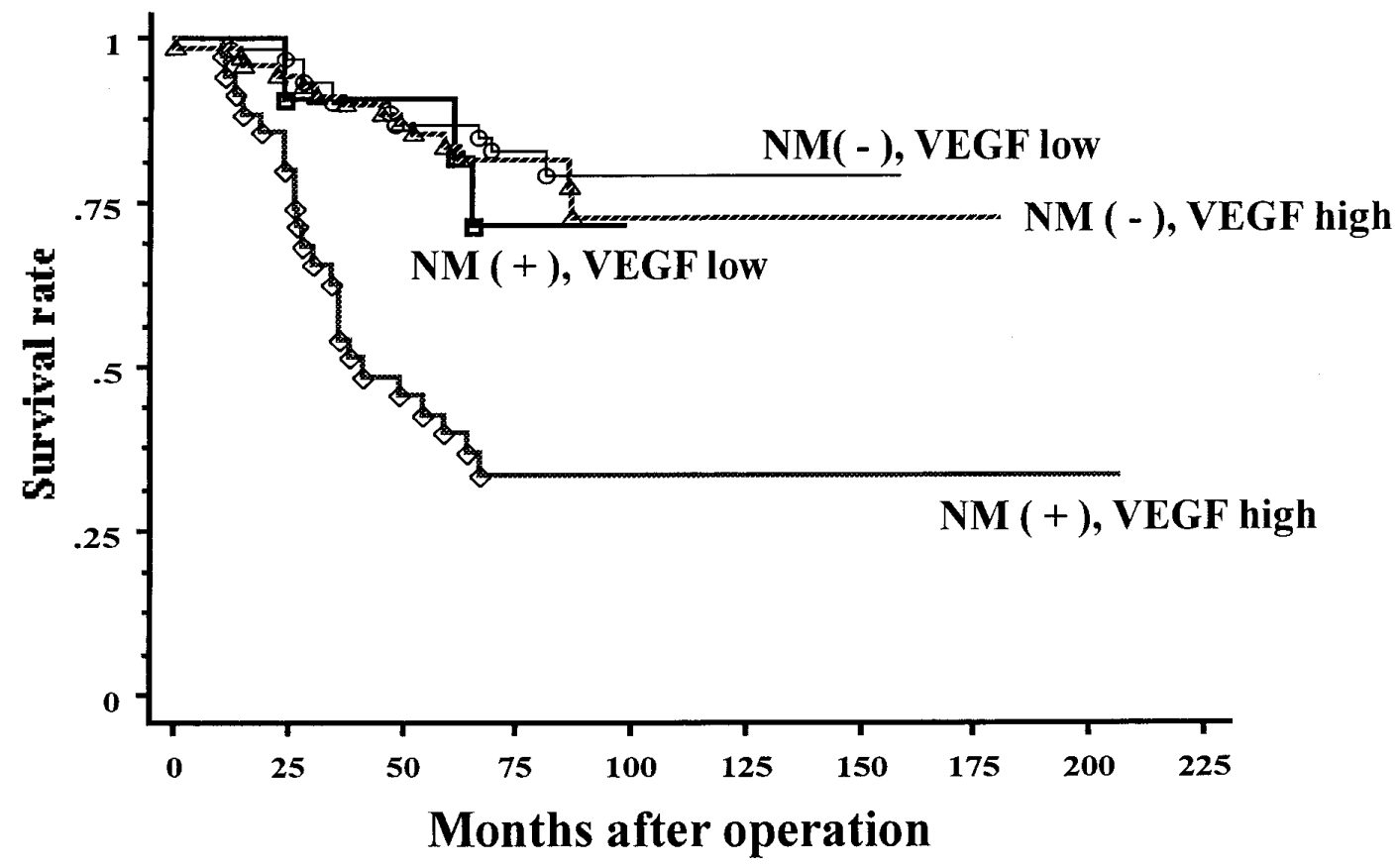

Figure 2. Kaplan-Meier survival plots for stage I NSCLCs subdivided according to NM status and VEGF expression level. A tumor was included in the VEGF-overexpressing group if the positive staining area in tumor cells was more than $50 \%$. Among the patients with NM, survival of the patients with VEGF overexpression was significantly worse than that of the patients without it $(P<.0001)$.

TABLE 4. Multivariate analysis by means of Cox proportional hazard regression model

\begin{tabular}{lllcr}
\hline & \multicolumn{3}{c}{ Characteristics } & \\
\cline { 2 - 5 } Factors & Unfavorable & Favorable & P value & Hazard ratio (95\% Cl) \\
\hline NM & Positive & Negative & .0004 & $2.874(1.604-5.149)$ \\
T factor & T2 & T1 & .0023 & $2.976(1.477-5.998)$ \\
VEGF* & High & Low & .0049 & $2.604(1.337-5.071)$ \\
Sex & Male & Female & .0083 & $2.507(1.267-4.960)$ \\
Blood vessel invasion & Positive & Negative & .0558 & $1.806(0.985-3.309)$ \\
Age (y) & $\geq 65$ & $<65$ & .3626 & $0.742(0.396-1.392)$
\end{tabular}

${ }^{*} A$ tumor was included in the VEGF-overexpressing group if the positive staining area in tumor cells was greater than $50 \%$.

various prognostic indicators assessed, age, sex, $\mathrm{T}$ factor, blood vessel invasion, NM, and VEGF had statistically significant values. As a result of multivariate analysis, $\mathrm{T}$ factor, NM, VEGF, and sex retained a significant independent prognostic effect on overall survival (Table 4).

\section{Discussion}

There seems to be general agreement that relapse after complete resection of a primary tumor in the early stage is a consequence of micrometastases that are present at the time of operation. A number of researchers have actually found the existence of small amounts of disseminated cancer cells in some distant organs, including lymph nodes, even in cases in which no metastasis was found by conventional examinations. Although the metastatic ability of these disseminated cancer cells is not fully understood, after the event of intravasation, most cancer cells have been found to undergo apoptosis or to remain in a dormant state, and very few cancer cells eventually succeed in the formation of established metastasis. ${ }^{9,10}$ In lymphatic systems, however, the movement of cancer cells is relatively slow through nodal stations. This less stressful situation of slow lymphatic flow may allow cancer cells a chance at the formation of nodal metastasis. ${ }^{10}$ To characterize disseminated occult cancer cells in lymph nodes, we previously studied the expression of some metastasis-associated markers, including angiogenesis and lymphangiogenesis 
stimulators, such as VEGF, VEGF-C, and $\mathrm{nm} 23$, in the primary site, and we found a significant association of these markers with NM and poor prognosis in NSCLC..$^{5}$ Although the presence of micrometastases does not affect cancer staging systems, we consider that patients with these disseminated cancer cells within lymph nodes belong to a high-risk group of recurrence, and detection of NM by using the immunohistochemical method used here should enable better stratification of patients with lung cancer in early stages of the disease.

Because of the spreading use of CT examinations and high-resolution $\mathrm{CT}$, the detection rate of small-sized peripheral lung cancer appears to be increasing. If there exists a critical tumor diameter less than which no lymph node metastasis will be found, it would be possible to treat smallsized peripheral lung cancer with minimally invasive procedures without systematic lymphadenectomy and with less concern about relapse. We previously performed a retrospective study on nodal status on the basis of the results of conventional histopathologic examination with hematoxylin and eosin staining. ${ }^{11}$ In that study the incidence of nodal metastasis in 524 patients with NSCLC with clinical stage I disease was $22 \%$. When stratified by histologic type, the frequency of nodal metastasis was $0 \%$ in tumors of less than $1.0 \mathrm{~cm}$ in diameter and $7.4 \%$ in those of 1.1 to $2.0 \mathrm{~cm}$ in diameter in squamous cell carcinoma. In adenocarcinoma the frequency was $0 \%$ in tumors of less than $1.0 \mathrm{~cm}$ and $20.8 \%$ in tumors of 1.1 to $2.0 \mathrm{~cm}$ in diameter. On the basis of these results, we suggested that systematic lymphadenectomy is dispensable in patients with peripheral squamous cell carcinoma of 2.0 $\mathrm{cm}$ or less in diameter and also in patients with adenocarcinoma of $1.0 \mathrm{~cm}$ or less in diameter. On the basis of the conventional histopathologic examination, Asamura and colleagues $^{12}$ found that the prevalence of nodal metastasis was relatively high, despite the small size of the primary tumor. According to their report, the frequencies of nodal involvement in patients with tumors of $2.0 \mathrm{~cm}$ or less in diameter were $6.3 \%$ in squamous cell carcinoma and $21.1 \%$ in adenocarcinoma. By meticulous examination of nodal involvement, they also found a low frequency of nodal involvement in squamous cell carcinoma of $2.0 \mathrm{~cm}$ or less in diameter. In the present study we assessed the spread of micrometastasis in patients in whom a diagnosis of N0 had been made on the basis of the results of conventional examination. Our findings concerning NM support the claim that a tumor diameter of $2.0 \mathrm{~cm}$ or less is a reliable criterion for selection of limited surgical intervention without lymphadenectomy for patients with squamous cell carcinoma. With regard to adenocarcinoma, however, the frequency of NM $(21.7 \%$ [23/106]) was high in patients in whom a diagnosis of N0 was made by means of conventional methods, even if the diameter of the primary tumor was $2.0 \mathrm{~cm}$ or less. In addition, the spread of NM was sometimes beyond the regional area, and so-called skipping metastasis was frequently found.
Notably, adenocarcinoma of $1.0 \mathrm{~cm}$ or less in diameter also retained a risk of NM (4/11) in our series. Although previous studies on the basis of conventional hematoxylin and eosin staining have suggested the propriety of limited surgical intervention without lymphadenectomy for patients with adenocarcinoma of $1.0 \mathrm{~cm}$ or less in diameter, ${ }^{11,13}$ our results indicated that a more prudent stance should be taken for adenocarcinoma. Nevertheless, NM was detected at a single level in all of 4 patients with adenocarcinoma of $1.0 \mathrm{~cm}$ in diameter, and the affected nodal area was localized within segmental nodes in 3 patients. The propriety of the criterion of $1.0 \mathrm{~cm}$ or less in adenocarcinoma warrants further study with a larger number of samples. In a cohort of patients with peripheral adenocarcinoma of $2 \mathrm{~cm}$ or less in diameter, we previously found that there was no NM in patients with localized bronchioloalveolar carcinoma or localized bronchioloalveolar carcinoma with foci of collapse of alveolar structure. ${ }^{14}$ Some patients with small-sized peripheral adenocarcinoma may benefit from limited surgical intervention if a reliable preoperative diagnostic method for the new histologic classification proposed by Noguchi and colleagues ${ }^{15}$ is developed.

The efficacy of systemic lymphadenectomy for NSCLC has been an issue of controversy. Among those who are against its therapeutic value, Izbicki and his colleagues ${ }^{16,17}$ found no prognostic advantage of radical lymphadenectomy in randomized controlled clinical trials with a cohort of patients with NSCLC. Sugi and coworkers ${ }^{18}$ also argued against the necessity of radical lymphadenectomy for peripheral small-sized NSCLC of less than $2.0 \mathrm{~cm}$ in diameter on the basis of a prospective randomized study. On the other hand, although mainly based on nonrandomized comparison, some investigators uphold the therapeutic value of radical systematic lymphadenectomy. ${ }^{19-21}$ Although controversy over the therapeutic value of lymphadenectomy remains, it is thought that standard resection, such as lobectomy plus radical lymphadenectomy, is the most reliable way to remove the local disease in patients with a risk of nodal involvement in the hilar or mediastinal area. Holding a risk of nodal involvement, some surgeons have advocated the usefulness of limited surgical intervention with minimal lung parenchymal resection. In proper selection of patients, although the final surgical results should be assessed in the long term, sublobar resections, such as segmentectomy with intraoperative exploration of nodal metastasis, have been reported to achieve comparable prognostic results compared with the results of lobectomy. ${ }^{22-26}$

Clearly, our results enlightened the evidence that the primary tumor size itself is not a reliable guide for NM status in adenocarcinoma. Therefore, a standard operation with systematic lymphadenectomy might still be a principal and a favorable surgical procedure for adenocarcinoma of more than $1.0 \mathrm{~cm}$ in diameter. 
Considering the fact that some patients still experienced relapse, mainly distant metastasis, despite complete resection of the primary tumor and systematic lymphadenectomy, discrimination of patients with a high risk of systemic disease also seems to be an important issue for the appropriate selection of patients for limited surgical intervention. From the results of this study, assessment of VEGF expression at the primary site appears to be useful for better stratification of patients with NM. Although the efficacy of adjuvant chemotherapy has not been fully substantiated, noncytotoxic therapies, including antiangiogenic therapies, may be effective therapeutic modalities.

Although the relations should be further explored in larger data sets, the following conclusions can be made from our study of the spread of NM in peripheral NSCLC. Limited surgical intervention without lymphadenectomy appears to be validated for squamous cell carcinoma of 2.0 $\mathrm{cm}$ or less in diameter. In adenocarcinoma tumor size itself is not a reliable guide for NM status. Because the presence of NM is an important prognostic indicator in NSCLC, we need to further examine the biologic behavior of small-sized adenocarcinoma for the proper selection of patients for limited surgical intevrention.

We thank Hiroyuki Nakamura, MD, DMedSc (Department of Public Health), for his review of statistical analysis and for help with manuscript preparation.

\section{References}

1. Chen Z-L, Perez S, Holmes EC, Wang H-J, Coulson WF, Wen D-R, et al. Frequency and distribution of occult micrometastases in lymph nodes of patients with non-small-cell lung carcinoma. J Natl Cancer Inst. 1993;85:493-8.

2. Izbicki JR, Passlick B, Hosch SB, Kubuschock B, Schneider C, Busch $\mathrm{C}$, et al. Mode of spread in the early phase of lymphatic metastasis in non-small cell lung cancer: significance of nodal micrometastasis. $J$ Thorac Cardiovasc Surg. 1996;112:623-30.

3. Maruyama R, Sugio K, Mitsudomi T, Saitoh G, Ishida T, Sugimachi $\mathrm{K}$. Relationship between early recurrence and micrometastases in the lymph nodes of patients with stage I non-small cell lung cancer. $J$ Thorac Cardiovasc Surg. 1997;114:535-43.

4. Nicholson AG, Graham ANJ, Pezzella F, Angeta G, Goldstraw P, Pastorino U. Does the use of immunohistochemistry to identify micrometastases provide useful information in the staging of nodenegative non-small cell lung cancer? Lung Cancer. 1997;18:231-40.

5. Ohta Y, Nozawa H, Tanaka Y, Oda M, Watanabe Y. Increased vascular endothelial growth factor and vascular endothelial growth factor-c and decreased nm23 expression associated with microdissemination in the lymph nodes in stage I non-small cell lung cancer. $J$ Thorac Cardiovasc Surg. 2000;119:804-13.

6. Huvos AG, Hutter RV, Berg JW. Significance of axillary macrometastases and micrometastases in mammary cancer. Ann Surg. 1971;173:44-6.

7. Ohta Y, Endo Y, Tanaka M, Shimizu J, Oda M, Hayashi Y, et al. Significance of vascular endothelial growth factor messenger RNA expression in primary lung cancer. Clin Cancer Res. 1996;2:1411-6.

8. Ohta Y, Tomita Y, Oda M, Watanabe S, Murakami S, Watanabe Y.
Tumor angiogenesis and recurrence in stage I non-small cell lung cancer. Ann Thorac Surg. 1999;68:1034-8.

9. Fidler IJ. Metastasis: quantitative analysis of distribution and fate of tumor emboli labeled with 125I-5-Iodo-2 deoxyuridine. J Natl Cancer Inst. 1970;45:773-82.

10. Condeelis JS, Whckoff J, Segall JE. Imaging of cancer invasion and metastasis using green fluorescent protein. Eur J Cancer. 2000;36: 1671-80.

11. Oda M, Watanabe Y, Shimizu J, Murakami S, Ohta Y, Sekido N, et al. Extent of mediastinal node metastasis in clinical stage I non-small-cell lung cancer: the role of systematic nodal dissection. Lung Cancer. 1998;22:23-30.

12. Asamura H, Nakayama H, Kondo H, Tsuchiya R, Simosato Y, Naruke T. Lymph node involvement, recurrence, and prognosis in resected small, peripheral, non-small cell lung carcinomas: Are these carcinomas candidates for video-assisted lobectomy? J Thorac Cardiovasc Surg. 1996;111:1125-34.

13. Konaka C, Ikeda N, Hiyoshi T, Tsuji K, Hirano T, Kawate N, et al. Peripheral non-small cell lung cancers $2.0 \mathrm{~cm}$ or less in diameter: proposed criteria for limited pulmonary resection based upon clinicopathological presentation. Lung Cancer. 1998;21:185-91.

14. Wu J, Ohta Y, Minato H, Tsunezuka Y, Oda M, Watanabe Y, et al. Nodal occult metastasis in patients with peripheral lung adenocarcinoma of $2.0 \mathrm{~cm}$ or less in diameter. Ann Thorac Surg. 2001;71:772-8.

15. Noguchi M, Morikawa A, Kawasaki M, Matsuno Y, Yamada T, Hirohashi S, et al. Small adenocarcinoma of the lung: histologic characteristics and prognosis. Cancer. 1995;75:2844-52.

16. Izbicki JR, Thetter O, Habekost M, Karg O, Passlick B, Kubuschok B, et al. Radical systematic mediastinal lymphadenectomy in non-small cell lung cancer: a randomized controlled trial. Br J Surg. 1994; 81:229-35

17. Izbicki JR, Passlick B, Pantel K, Pichlmeier U, Hosch SB, Karg O, et al. Effectiveness of radical systematic mediastinal lymphadenectomy in patients with resectable non-small cell lung cancer: results of a prospective randomized trial. Ann Surg. 1998;227:138-44.

18. Sugi K, Nawata K, Fujita N, Ueda K, Tanaka T, Matsuoka T, et al. Systematic lymph node dissection for clinically diagnosed peripheral non-small-cell lung cancer less than $2 \mathrm{~cm}$ in diameter. World $J$ Surg. 1998;22:290-5.

19. Martini N, Flehinger BJ, Zaman MB, Beattie EJ. Results of resection in non-oat cell carcinoma of the lung with mediastinal lymph node metastases. Ann Surg. 1983;198:386-97.

20. Naruke T, Goya T, Tsuchiya R, Suemasu K. The importance of surgery to non-small cell carcinoma of lung with mediastinal lymph node metastasis. Ann Thorac Surg. 1988;46:603-9.

21. Keller SM, Adak S, Wagner H, Johnson DH. Mediastinal lymph node dissection improves survival in patients with stage II and IIIa nonsmall cell lung cancer. Ann Thorac Surg. 2000;70:358-66.

22. Read RC, Yoder G, Schaeffer RC. Survival after conservative resection for T1N0M0 non-small cell lung cancer. Ann Thorac Surg. 1990; 49:391-8.

23. Warren WH, Faber LP. Segmentectomy versus lobectomy in patients with stage I pulmonary carcinoma: five-year survival and patterns of intrathoracic recurrence. J Thorac Cardiovasc Surg. 1994;107:108794.

24. Kodama K, Doi O, Higashiyama M, Yokouchi H. Intentional limited resection for selected patients with T1 N0 M0 non-small cell lung cancer: a single-institution study. J Thorac Cardiovasc Surg. 1997; 114:347-53

25. Tsubota N, Ayabe K, Doi O, Mori T, Namikawa S, Taki T, Watanabe Y. Ongoing prospective study of segmentectomy for small lung tumors: study of extended segmentectomy for small lung tumor. Ann Thorac Surg. 1998;66:1787-90.

26. Okada M, Yoshikawa K, Hatta T, Tsubota N. Is segmentectomy with lymph node assessment an alternative to lobectomy for non-small cell lung cancer of $2 \mathrm{~cm}$ or smaller? Ann Thorac Surg. 2001;71:956-60. 